\title{
LOURENÇO FILHO E O BOLETIM “ORGANIZAÇÃO DO ENSINO PRIMÁRIO E NORMAL” EM MATO GROSSO
}

\author{
Lourenço Filho and the Newsletter "Organização do ensino primário e normal" in \\ Mato Grosso \\ Lourenço Filho y el Boletín "Organização do Ensino Primário e Normal” en Mato \\ Grosso
}

Estela Natalina Mantovani Bertoletti*

Ademilson Batista Paes**

\begin{abstract}
Resumo
Este artigo tem como objetivo analisar aspectos do Boletim n. 22, "Organização do Ensino Primário e Normal - XVII. Estado de Mato Grosso", dirigido por Manoel Bergström Lourenço Filho (1897-1970) e publicado em 1942. Os dados organizados nesse Boletim trazem características da educação mato-grossense, do ponto de vista dos órgãos oficiais que dão a conhecer a situação da educação naquele estado, nos anos de 1930 a 1940. Dentre esses aspectos, podemos destacar a análise de Lourenço Filho sobre o aumento quantitativo do ensino primário em Mato Grosso, não acompanhado, a seu ver, de aumento qualitativo de rendimento escolar.
\end{abstract}

PALAVRAS-CHAVE: Lourenço Filho. Ensino primário. Ensino normal.

\begin{abstract}
This article aims analyze aspects of the Newsletter n. 22, "Organização do Ensino Primário e Normal - XVII. Estado de Mato Grosso", directed by Manoel Bergström Lourenço Filho (18971970) and published in 1942. The data organized in Newsletter n. 22 bring characteristics of education, from official organs of Mato Grosso that give the situation of education in that State, corresponding to the years of 1930 to 1940. Among these aspects, we can highlight the analysis of Lourenço Filho on the quantitative increase of the elementary school in Mato Grosso, from the expansion of resources for education, unaccompanied, however, qualitative growth of school performance.
\end{abstract}

KEYWORDS: Lourenço Filho. Elementary School. Normal School.

\section{Resumen}

Este artículo tiene como objetivo analizar aspectos del Boletín No. 22, "A organização do Ensino Primário e Normal - XVII. Estado de Mato Grosso ", dirigida por Manoel Bergström Lourenço Filho (1897-1970) y publicado en 1942. Los datos organizados en este Boletín traen características

\footnotetext{
* Doutora em Educação (Unesp/Marília) / Pós-Doutorado em Educação Escolar (Unesp/Araraquara) / PósDoutorado em Educação (UERJ). Professora Adjunta da Universidade Estadual de Mato Grosso do Sul (UEMS). Coordenadora do Programa de Pós-Graduação em Educação (UEMS/Paranaíba). estelanmb@gmail.com

** Doutor em Educação Escolar (Unesp/Araraquara) / Pós-Doutorado em Educação (UFGD). Professor Adjunto da Universidade Estadual de Mato Grosso do Sul (UEMS). E-mail: abpaesbr@yahoo.com.br
} 
de la educación de Mato Grosso, desde el punto de vista de los organismos oficiales para dar a conocer la situación de la educación en este estado, entre los años de 1930 y 1940.Entre otros aspectos, podemos destacar el análisis de Lourenço Filho con respecto al aumento cuantitativo de la enseñanza primaria en Mato Grosso, noacompañado, en su opinión, de un aumento cualitativo en el rendimiento escolar.

PALABRAS CLAVE: Lourenço Filho. Educación primaria. Estudio del magisterio.

\section{INTRODUÇÃO}

O presente texto tem como foco de análise o Boletim n. 22, "Organização do Ensino Primário e Normal - XVII. Estado de Mato Grosso", dirigido por Manoel Bergström Lourenço Filho (1897-1970) e publicado em 1942, quando o educador ocupava a função de Diretor do Instituto Nacional de Estudos Pedagógicos (INEP) ${ }^{1}$.

Consideramos que o Boletim n. 22 foi produzido no âmbito de uma prática de boletins que visavam a organizar e divulgar dados relativos à educação brasileira, prática característica do órgão que o publicou, o INEP, bem como de seu diretor, Lourenço Filho. Além disso, podemos afirmar que os dados organizados no Boletim n. 22 trazem aspectos da educação mato-grossense, advindos dos órgãos oficiais que dão a conhecer a situação da educação naquele estado, correspondente aos anos de 1930 a 1940.

Assim, a análise proposta do Boletim n. 22 sobre a organização do ensino primário e normal de Mato Grosso cumpre a função não somente de divulgar um dos inúmeros trabalhos realizados no INEP na figura de Lourenço Filho, como também busca compreender um dos capítulos da história da educação daquele estado e do Brasil, de como se encontrava a educação e o que se propunha para ela.

\section{Lourenço Filho e o INEP}

Lourenço Filho esteve à frente do INEP já a partir do momento de sua criação em 1937, mediante convite de Gustavo Capanema, então ministro da Educação e Saúde, para organizar o Instituto criado por meio do Decreto-Lei n. 580 de 30 de julho de 1938, e assumiu o cargo de Diretor de 1938 a 1946. O principal objetivo do INEP era realizar pesquisas sobre a educação, além de constituir-se como centro de assuntos educacionais relacionados com atividades do Ministério da Educação e Saúde e cooperar com o Departamento Administrativo do Serviço Público (DASP) ${ }^{2}$, voltado para ações de estudos e trabalhos relacionados à seleção, ao aperfeiçoamento e à readaptação do quadro de

\footnotetext{
${ }^{1}$ O INEP foi criado pela Lei n. 378, de 13 do janeiro de 1937, sendo denominado Instituto Nacional de Pedagogia. Em 1938, por meio do Decreto-Lei n. 538, de 30 de julho, passou a ser denominado Instituto Nacional de Estudos Pedagógicos e, a convite do ministro Gustavo Capanema Lourenço Filho o organizou e dirigiu, até 1946. A partir de 1972, passou a ser denominado Instituto Nacional de Estudos e Pesquisas Educacionais.

${ }^{2}$ O DASP foi criado pelo Governo Vargas, por meio do Decreto-Lei n. ${ }^{\circ}$ 579, de 30/07/1938, e foi desde seu início subordinado diretamente ao Presidente da República.
} 
funcionalismo da União (LOURENÇO FILHO, 2005) ${ }^{3}$. Dentre as funções do INEP preconizadas no Decreto-Lei mencionado encontravam-se aquelas que diziam respeito à organização de documentos relativos ao estudo de técnicas pedagógicas e das instituições educativas; ao fomento e à manutenção de intercâmbio com instituições de ensino no país e no exterior; à promoção de pesquisas sobre problemas atinentes ao ensino, no campo da psicologia, como também da orientação e seleção profissional; à prestação de assistência técnica relativa à educação no âmbito estadual, municipal e particular; à divulgação de conhecimentos e pesquisas acerca da teoria e prática pedagógica, além do "Serviço de Biometria Médica", mecanismo auxiliar na seleção de recursos humanos para o funcionalismo público, anos mais tarde deslocado para o DASP. (BRASIL, 1938, n.p.)

Importa salientar que Lourenço Filho imprimiu sua marca desde o início da atuação no INEP, a partir do ano de 1938. Dotado de rara capacidade de trabalho (BERTOLETTI, 2006), com tendência para racionalização do trabalho educacional, formou-se professor primário, em 1914, na Escola Normal Primária, de Pirassununga/SP; professor secundário, em 1917, na Escola Normal Secundária, de São Paulo/SP; e bacharel em Ciências Jurídicas e Sociais, em 1929, na Faculdade de Direito de São Paulo/SP. Ao longo de sua vida e formação, exerceu inúmeras e diversificadas atividades didáticas, administrativas e intelectuais, sobre variados temas, em uma intensa carreira ${ }^{4}$, voltada para os problemas da educação onde eles aconteciam: no espaço escolar.

Sua atuação foi orientada por ideias que instituiu e divulgou juntamente com outros intelectuais da época, como Anísio Teixeira e Fernando de Azevedo, ligadas ao movimento denominado de Escola Nova que, segundo seus protagonistas, propunha um novo tratamento aos problemas da educação, no sentido de difundir a instrução elementar, opondo-se às formas tradicionais de ensino, tendo como consequência a reforma da sociedade.

Em vista disso, junto ao INEP, Lourenço Filho dirigiu um sem-número de atividades, desde a coleta de material e de dados, até a coordenação e disposição desses em "[...] indagações úteis aos problemas de eficiência de ensino e mais questões educacionais, de qualquer natureza" (LOURENÇO FILHO, 2005, p. 183).

Junto a cada departamento ou setor da educação dos estados coletava-se mensalmente o que dizia respeito à vida educacional das unidades federadas, sendo que:

Direta ou indiretamente, todas as instituições de educação do país entraram em relação com o INEP. Particularmente, porém, procurava-se manter relações mais constantes com os centros de administração do ensino, órgãos técnicos, órgãos de ensino pedagógico especializado (como escolas normais e as Seções de Educação das faculdades de filosofia) e, ainda, associações de educadores (CARVALHO, 1959, p. 91).

Dessa forma, tal intercâmbio ocorrido com os estados e o INEP, acabou por fornecer a este, material volumoso e considerável número de documentos que propiciavam

\footnotetext{
${ }^{3}$ Publicado originalmente na Revista Brasileira de Estudos Pedagógicos, v. 42, n. 95, p. 8-17, jul./set. 1964.

${ }^{4}$ Dados biográficos e bibliográficos de e sobre Lourenço Filho podem ser encontrados, especialmente, em Monarcha e Lourenço Filho (2001).
} 
compreensão mais próxima de como se encontrava a área da educação nas diversas regiões do país, naquele período. Tal material acabou compondo os relatórios, boletins e informativos distribuídos pelo Instituto, às próprias regiões que os haviam fornecido:

O movimento desse intercâmbio com as instituições de educação do país correspondeu, em média, a três quartas partes de todo o movimento de correspondência anual do Instituto. Por essa forma, constituiu-se o INEP como centro de documentação de toda a educação do país e órgão informativo geral. Cada mês, remetia ele a todos os órgãos de administração do ensino nos estados e territórios e aos principais órgãos de imprensa um boletim impresso, com o extrato de toda a documentação recolhida e classificada no mês anterior. (CARVALHO, 1959, p. 91).

Além disso, houve o intercâmbio com esferas de atuação semelhante à do INEP, no exterior, como ministérios da educação, universidades, escolas de formação de professores, associações e professores renomados em seus países, estabelecendo intensa troca epistolar, chegando às centenas o material recebido. Essa realidade já comprova a atuação de Lourenço Filho que por meio de seu dinamismo e fôlego imprimiu ritmo ao Instituto. Tais contatos resultaram quase sempre em visitas de representantes da área da educação de outros países ao INEP, como ministros de Estados (Bolívia, Paraguai), diretores de Departamentos de Educação (Argentina, Chile, Uruguai, Equador, Venezuela, França, EUA), de professores (Howard University, Harvard Univesity, Univesity of Wisconsin, Louisianne State Univesity e University of Pennsylvania), representantes de instituições (Rockfeller Foundation, Interamerican Education Foundatin), entre muitos outros (CARVALHO, 1959, p. 92).

Outras frentes de atuação e trabalho desencadeadas no interior do INEP foram aquelas que diziam respeito a inquéritos e pesquisas, responsáveis por levantamentos periódicos sobre temas específicos no campo educacional, como: despesas com serviços educacionais, remuneração dos professores tanto da rede pública, quanto da iniciativa privada, construções escolares, movimento de órgãos auxiliares da escola, como caixa escolar, cooperativas, clubes de alunos. Tais inquéritos demandaram tempo e foram constituídos na sequência de anos de trabalho.

\footnotetext{
Investigação sobre revistas e jornais infantis e juvenis, editados no Rio de Janeiro; investigações sobre a linguagem pré-escolar; investigações sobre o vocabulário ativo da criança na idade escolar; investigação sobre o vocabulário comum do adulto; investigações sobre a remuneração dos professores em estabelecimentos oficiais de ensino nos anos de 1939, 1941 e 1944; levantamento das oportunidades educacionais na capital do país; levantamento do curso de ensino, no país e no estrangeiro, em estabelecimentos públicos e particulares; levantamento da bibliografia pedagógica brasileira, a partir de 1812 (primeiros documentos encontrados) até o ano de 1943. (CARVALHO, 1959, p. 92-93).
}

O campo da assistência e cooperação técnica foi outra frente amplamente desenvolvida pelo INEP quando da gestão de Lourenço Filho, visando a dar orientação e assessoria a órgãos, secretarias, departamentos, professores da esfera pública e privada, traduzidos em planos de reformas de administração escolar no Brasil e exterior, estudos de orientação didática, preparação de provas tendo em vista a verificação do ensino e cursos 
de orientação. Nesse item de assessoramento e orientação, com o fim de reorganização da instrução pública estadual, constam o Plano Geral de Reorganização das Secretarias de Educação do Rio Grande do Sul, Paraíba, Goiás, Bahia, Paraná, Acre, além desses os dos Territórios de Guaporé, Ponta Porã, Rio Branco, Amapá; estudos relativos à reorganização da educação no Paraguai (1945); à organização do serviço de inspeção escolar no Piauí, Maranhão e Alagoas; elaboração de provas objetivas para verificação da aprendizagem nas escolas primárias do Espírito Santo (1943 e 1944), Guaporé, Rio Grande do Sul (1943), Rio de Janeiro (1934 e 1944); cooperação no estudo de um "Código de Classificação de livros e publicações periódicas", pelo DASP; cooperação com a "Cruzada Nacional de Educação"; estudo acerca da educação rural no Brasil, conforme solicitação pela Missão Técnica Norte-americana, chefiada por M. Cooke; colaboração com a reorganização da Faculdade de Filosofia, em Assunção, Paraguai; estudos tendo em vista a reorganização do Ministério do Paraguai (1945). (CARVALHO, 1959, p. 95).

Pelo exposto, nota-se a importância do INEP e da igual característica de seu diretor, o educador Lourenço Filho, detentor de ampla e vasta obra no campo educacional brasileiro, resultante de sua precoce inserção e engajamento no meio educacional, e que, juntamente com Anísio Teixeira e Fernando de Azevedo, formou respeitável segmento de pensadores da educação no período designado de Segunda República.

\section{O INEP, a prática de "Boletim" e o Boletim n. 22}

A série nomeada pelo INEP como "Boletim" foi iniciada em 1939, apresentando até o ano de $1942^{5}, 24$ publicações, cujos conteúdos variavam, entre outros, em apontamentos, diagnósticos, dados estatísticos e históricos, ilustrações, fotografias e indicações acerca da educação brasileira, principalmente no que diz respeito às décadas de 1930 a 1950, a saber: Boletim n. 01 "O ensino no Brasil no quinquênio 1932-1936"; Boletim n. 02 "Organização do ensino primário e normal - I. Estado do Amazonas"; Boletim n. 03 "Organização do ensino primário e normal - II. Estado do Pará"; Boletim n. 04 "Organização do ensino primário e normal - III. Estado do Maranhão"; Boletim n. 05 "Organização do ensino primário e normal - IV. Estado do Piauí"; Boletim n. 06 "Organização do ensino primário e normal - V. Estado do Ceará"; Boletim n. 07 "Organização do ensino primário e normal - VI. Estado do Rio Grande do Norte"; Boletim n. 08 "Organização do ensino primário e normal - VII. Estado da Paraíba"; Boletim n. 09 "Organização do ensino primário e normal - VIII. Estado de Pernambuco"; Boletim n. 10 "Organização do ensino primário e normal - IX. Estado de Alagoas". Boletim n. 11 "Organização do ensino primário e normal - X. Estado de Sergipe"; Boletim n. 12 "A administração dos Serviços de Educação"; Boletim n. 13 "Situação geral do ensino primário"; Boletim n. 14 "Organização do ensino primário e normal - XII. Estado da Baía”; Boletim n. 15 "Organização do ensino primário e normal - XII. Estado do Espírito Santo"; Boletim n. 16 "Organização do ensino primário e normal - XIII Estado do Rio de Janeiro"; Boletim n. 17 "Subsídios para a História da Educação Brasileira I, ano de 1940"; Boletim n. 18 "Subsídios para a História da Educação Brasileira, II, Ano de 1941";

\footnotetext{
5 Segundo Carvalho (1959), os boletins expedidos pelo INEP somaram 102, entre impressos e mimeografados.
} 
Boletim n. 19 "Organização do ensino primário e normal - XIV Estado de São Paulo"; Boletim n. 20 "Organização do ensino primário e normal - XV. Estado do Paraná"; Boletim n. 21 "Organização do ensino primário e normal - XVI. Estado de Santa Catarina"; Boletim n. 22 "Organização do ensino primário e normal - XVII. Estado de Mato Grosso"; Boletim n. 23 "Organização do ensino primário e normal - XVIII. Estado de Goiaz"; e, Boletim n. 24 "Organização do ensino primário e normal - XIX. Estado de Minas Gerais".

Como já se ressaltou, as publicações, traduzidas em boletins e outros impressos acompanharam as ações do INEP desde sua origem, cuja culminância se deu a partir de 1944, com a publicação da Revista Brasileira de Estudos Pedagógicos. Por meio dessas publicações, desenvolveu-se um lócus privilegiado de proposições e debates acerca da educação brasileira.

No que diz respeito somente aos boletins sobre a organização do ensino primário e normal nos estados brasileiros, foram publicados em duas etapas, sendo de 1939 a 1945, a primeira, na qual se inclui o boletim sobre o estado de Mato Grosso, e de 1950, a segunda ${ }^{6}$. Esses boletins tiveram a finalidade de documentar a

[...] situação da educação nas várias unidades federadas, e descrevem as instituições encarregadas da realização do ensino primário e normal; indicam os princípios e normas que os regem; salientam o alcance social de cada uma das instituições; apresentam os planos de formação do magistério e as bases da carreira do professor. (BRASIL, 2004, n.p.)

O Boletim n. 22 sobre a organização do ensino primário e normal do estado de Mato Grosso é composto por 37 páginas, sendo dividido em Introdução assinada por Lourenço Filho; 15 tópicos não numerados, contendo dados sobre o estado de Mato Grosso relativos à administração da educação, aos órgãos técnicos centrais, à formação e carreira do professor primário, à escola primária, à obrigatoriedade escolar, à inspeção, à assistência médica e dentária, a instituições de assistência escolar, a edificações e aparelhamento escolares, a despesas com o ensino primário e normal, ao ensino municipal e particular, à nacionalização do ensino e ao ensino primário para adultos; e, um anexo com dados estatísticos sobre o estado de Mato Grosso.

Todos esses dados foram recolhidos e organizados, em 1939, ao que tudo indica, pela Seção de Documentação e Intercâmbio do INEP, representada pelo Dr. Rui Guimarães de Almeida, a partir dos seguintes documentos: Decreto n. 759 de 22 de abril de 1927; Decreto n. 125, de 27 de janeiro de 1932; Decreto n. 283, de 4 de julho de 1933; Decreto n. 112, de 29 de dezembro de 1937; Decreto n. 226, de 23 de dezembro de 1938; Decreto n. 229, de 27 de dezembro de 1938; e, Decreto n. 229, de 27 de dezembro de 1938, produzidos pelo estado de Mato Grosso, além do Serviço de Estatística da Educação e

\footnotetext{
${ }^{6}$ Foram também publicados os seguintes: Boletim n. 28 "Organização do ensino primário e normal - XX. Estado do Rio Grande do Sul”, em 1945; Boletim n. 52 "Organização do ensino primário e normal - XXI. Estado do Piauí"; Boletim n. 53 "Organização do ensino primário e normal - XXII. Estado de Santa Catarina”; Boletim n. 54 "Organização do ensino primário e normal - XXIII. Estado de Sergipe”; Boletim n. 57 “Organização do ensino primário e normal - XXIV. Estado do Espírito Santo”; Boletim n. 62 “Organização do ensino primário e normal - XXV. Estado da Paraíba”, todos em 1950.
} 
Saúde do mesmo estado. Tais dados foram submetidos, por ordem do diretor do INEP, Lourenço Filho, em 23 de setembro de 1939, ao Diretor-Geral da Instrução Pública de Mato Grosso, Francisco Alexandre Ferreira Mendes, que deu seu visto em 28 de outubro de 1938.

De posse dos dados, vistos e autorizados, Lourenço Filho produziu a Introdução do Boletim para sua publicação, assinada em outubro de 1942. Na Introdução, Lourenço Filho (1942) fez uma síntese e um balanço quantitativo e qualitativo do panorama geral da instrução pública e particular relativamente ao ensino primário e normal em terras matogrossenses, além de trazer prescrições para "[...] que novos esforços sejam aplicados no sentido de elevação da eficiência e do sentido social da educação primária [...]" (LOURENÇO FILHO, 1942, p. 9), em Mato Grosso.

Iniciou apresentando dados e informações que reforçavam seu argumento acerca do "território, ainda em grande parte a ser povoado", ressaltando que a parte sul do estado apresentava "núcleos de população menos dispersos", e destacou que o ensino nos últimos dez anos adquirira desenvolvimento quantitativo. A partir daqueles, fez comparação entre dois períodos da década mencionada, como seguem expostos no Quadro 1:

Quadro 1 - Instrução em Mato Grosso (1932-1942)

\begin{tabular}{|c|c|c|c|}
\hline Ano & $\begin{array}{c}\text { Escolas - Públicas e } \\
\text { particulares }\end{array}$ & $\begin{array}{c}\text { Matrícula - } \\
\text { alunos }\end{array}$ & $\begin{array}{c}\text { Ensino } \\
\text { Municipal - } \\
\text { escolas }\end{array}$ \\
\hline 1932 & 238 & 16.407 & 08 \\
\hline 1941 & 336 & 28.223 & 64 \\
\hline
\end{tabular}

Fonte: Boletim n. 22, Brasil (1942).

Como se pode observar, os dados do Quadro 1 apresentam certo crescimento e desenvolvimento do campo da instrução em Mato Grosso, no que diz respeito ao aumento do número de escolas e de matrículas, fato, aliás, que acompanhou a tônica de todo o país. Não se pode desconsiderar que as décadas de 1930 e 1940 foram extremamente férteis em debates, reformas, propostas e inúmeras medidas que visavam a uma guinada qualitativa no campo. O governo central, por sua vez, criou organismos e ações que contribuíam nesse sentido, como o repasse financeiro aos estados, por meio de convênios para a construção de escolas urbanas e rurais, celebrados com os governos estaduais, em parceria com o Fundo Nacional de Ensino Primário, vinculado ao INEP. Na análise de Lourenço Filho esse crescimento e desenvolvimento deveriam ser atribuídos ao "[...] esfôrço da administração estadual em aumentar, cada ano, os recursos destinados ao ensino" (LOURENÇO FILHO, 1942, p. 7), porém, a seu ver, o progresso quantitativo não vinha acompanhado de progresso qualitativo.

Para Lourenço Filho (1942), o anacronismo na legislação e na orientação pedagógica revelava-se como entrave na organização do ensino primário e normal em Mato Grosso.

A organização do ensino, como se vê pela súmula da legislação contida neste boletim, é das mais singelas; o ensino primário obedece ainda a um regulamento datado de 1927. [...] Deve-se confessar, [...] que os programas e a orientação geral do ensino estão a exigir revisão, para que melhor se adaptem às 
necessidades gerais da vida, do Estado e às peculiaridades de trabalho, em cada uma de suas distintas zonas de produção. (LOURENÇO FILHO, 1942, p. 8)

$\mathrm{Na}$ verdade, ao que tudo indica, Lourenço Filho (1942) criticava, sobretudo, o método de ensino da leitura que em Mato Grosso vinha oficialmente pautado no método analítico, haja vista que para esse educador não somente a questão dos métodos, como também quaisquer aspectos externos ao aprendizado do aluno, era relativa e secundária, sendo, a seu ver, a maturidade biofisiológica da criança condição necessária para se aprender a ler e a escrever ${ }^{7}$. Dessa feita, para Lourenço Filho (1942) havia a necessidade de ações "de mais intensa ação social", como eram as "missões culturais" ou as "colôniasescola", além da participação de "instituições complementares à escola" no incremento da educação em solo mato-grossense. Para ele, no entanto, tudo isso dependia de "mais adequada preparação dos mestres".

Embora os esforços a respeito da formação e carreira do professor primário, já se encontrassem presentes na reforma da instrução pública preconizada no Regulamento da Instrução Pública Primária do Estado de Mato Grosso, de 1910, e na reforma de 1927 no Regulamento da Instrução Pública Primária do Estado que enfatizava que o provimento de professores deveria ocorrer por meio de concurso e que todos fossem normalistas, percebese que na década de 1940 eles ainda se encontravam em debate. No período, a presença de professores interinos era de considerável porcentagem, ainda que existissem os efetivos e substitutos. O que se percebe é que, entre o prescrito e o praticado houve, naturalmente, inúmeros descaminhos e entraves. Os cursos normais de Campo Grande e Cuiabá não conseguiam atender a todas as necessidades de escolas primárias dispersas pelo estado, cuja realidade era composta por dificuldades, a começar, por exemplo, por colocar as normalistas à frente das centenas de escolas isoladas rurais, reunidas e grupos escolares. Embora haja notícias de que as primeiras normalistas de Cuiabá chegaram ao interior do estado nos anos de 1940 e 1950, isso era feito de forma exígua e insuficiente para atender à demanda crescente de crianças às portas das escolas. Não é por acaso que é justamente nesse período que ocorreu em Mato Grosso a ampliação da presença de congregações católicas e de confissão protestante, na criação e manutenção de escolas primárias não só na capital, como também nas principais cidades mato-grossenses. Sobre a questão do meio rural, percebe-se que a normatização para o provimento das cadeiras de professores revela certa incoerência do legislador, uma vez que no corpo da reforma de 1927, prescreveu-se que os cargos seriam preenchidos por meio de concurso público para normalistas. Entretanto, nesse meio, primeiramente a escola isolada deveria funcionar com um professor interino e somente após um ano de existência ela poderia receber um professor efetivo, como se pode observar no Art. 49:

Art. 49 - a escola isolada rural só será efetivamente provida depois de um ano de funcionamento com provimento interino, verificando-se que o número de crianças existentes no raio escolar é suficiente para alimentar a frequência legal da escola. (MATO GROSSO, 1927, n.p.)

\footnotetext{
${ }^{7}$ Para aprofundamento sobre o pensamento de Lourenço Filho em relação ao aprendizado da leitura e da escrita ver, sobretudo: Mortatti (2000) e Bertoletti (2006).
} 
Assim, pode-se observar a precariedade do ensino normal em Mato Grosso pelo reduzido número de escolas, conforme os dados do Quadro 2.

Quadro 2 - Ensino Normal - 1937 - Mato Grosso

\begin{tabular}{|c|c|c|c|c|}
\hline $\begin{array}{c}\text { Dependência } \\
\text { Administrativa }\end{array}$ & Unidades Escolares & $\begin{array}{c}\text { Corpo } \\
\text { Docente }\end{array}$ & $\begin{array}{c}\text { Matrícula } \\
\text { Geral }\end{array}$ & $\begin{array}{c}\text { Conclusões do } \\
\text { Curso }\end{array}$ \\
\hline Estadual & 02 & 29 & 447 & 31 \\
Particular & 01 & 10 & 90 & 20 \\
\hline Total Geral & 03 & 39 & 537 & 51 \\
\hline
\end{tabular}

Fonte: Boletim n. 22, Brasil (1942).

Lourenço Filho (1942) atribuiu a essa situação a responsabilidade pelo "deficiente rendimento escolar" em Mato Grosso, apontando como necessária a criação de cursos normais de "cunho mais simples", sem, no entanto, descrever como deveria ser essa organização. Para o autor: "No triênio 1939-1941 os alunos aprovados não chegavam a representar metade da matrícula efetiva; em relação à matrícula geral, os alunos só chegavam a ser promovidos em um têrço." (LOURENÇO FILHO, 1942, p. 9). Assim, o crescimento que se pode observar no Quadro 3, não tinha muita representatividade aos olhos de Lourenço Filho.

Quadro 3 - Movimento Geral - Ensino Primário (Comum e Supletivo)

De 1932 a 1939

\begin{tabular}{|l|c|c|c|c|c|c|c|c|}
\hline & $\mathbf{1 9 3 2}$ & $\mathbf{1 9 3 3}$ & $\mathbf{1 9 3 4}$ & $\mathbf{1 9 3 5}$ & $\mathbf{1 9 3 6}$ & $\mathbf{1 9 3 7}$ & $\mathbf{1 9 3 8}$ & $\mathbf{1 9 3 9}$ \\
\hline Unidades Escolares & 242 & 305 & 327 & 368 & 390 & 428 & 377 & 378 \\
\hline Corpo Docente & 454 & 622 & 694 & 737 & 718 & 793 & 724 & 714 \\
\hline Matrícula Geral & 16.791 & 20.888 & 22.647 & 26.515 & 28.203 & 28.120 & 26.193 & 27.774 \\
\hline Aprovações em Geral & - & 11.687 & 14.818 & 16.243 & 18.655 & 14.840 & 15.003 & 10.457 \\
\hline
\end{tabular}

Fonte: Boletim n. 22, Brasil (1942).

De todo modo, interessante é observar duas novidades no Boletim n. 22, que foram aquelas dedicadas ao Ensino Municipal e ao Ensino Particular. Não houvera até aquele período nenhuma informação de seu quantitativo ou situação no estado. Com o Boletim, no entanto, houve não somente a denominação em escolas isoladas rurais, isoladas urbanas, cursos noturnos, escolas reunidas e grupos escolares, como também sua definição e a apresentação de dados estatísticos, nas três esferas administrativas, como os que seguem organizados no Quadro 4:

Quadro 4 - Ensino Primário Geral - 1937 - Mato Grosso

\begin{tabular}{|l|c|c|c|}
\hline Unidades Escolares & Esfera administrativa & Total & $\begin{array}{c}\text { Total } \\
\text { Geral }\end{array}$ \\
\hline Grupos Escolares & Estadual & 11 & 11 \\
\hline Escolas Reunidas & Estadual & 14 & 14 \\
\hline Escolas Isoladas & $\begin{array}{l}\text { Estadual } \\
\text { Municipal } \\
\text { Particular }\end{array}$ & $\begin{array}{c}62 \\
150\end{array}$ & 403 \\
\hline
\end{tabular}




\begin{tabular}{|l|l|c|c|}
\hline & Estadual & 446 & \\
Corpo Docente & Municipal & 70 & 793 \\
& Particular & 277 & \\
\hline & Estadual & 15.605 & \\
Matrícula Geral & Municipal & 2.905 & 28.210 \\
& Particular & 9.610 & \\
\hline
\end{tabular}

Fonte: Boletim n. 22, Brasil (1942).

Além disso, o programa do ensino primário foi também explicitado no Boletim, a saber:

$1^{\circ}$ ano - Leitura e linguagem oral e escrita; aritmética; geografia; ciências físicas e naturais; educação higiênica; instrução moral e cívica; desenho; trabalhos manuais; canto.

$2^{\circ}$ ano - Leitura e linguagem oral e escrita; aritmética; geografia; história do Brasil; educação moral e cívica; desenho; educação higiênica; trabalhos manuais; educação física.

$3^{\circ}$ ano - Leitura e linguagem oral e escrita; aritmética; geografia e cosmografia; história do Brasil; instrução moral e cívica; geometria e desenho; ciências naturais; higiene.

$4^{\circ}$ ano - Leitura e linguagem oral e escrita; aritmética; geografia e cosmografia; história do Brasil; ciências físicas e naturais; instrução moral e cívica; geometria e desenho; educação higiênica; trabalhos manuais. (BRASIL, 1942, p. 17).

Embora, como já ressaltado, Lourenço Filho (1942) tenha sido enfático na Introdução do Boletim n. 22 ao afirmar textualmente que os programas e a orientação geral do ensino carecessem de revisão para melhor adaptação às necessidades e peculiaridades do estado, $o$ educador salientou os esforços da administração do estado de Mato Grosso no sentido de desenvolvimento do ensino e reconheceu que Mato Grosso não era o único estado do país a exigir reajustamento do ensino, mas todas as regiões de baixa densidade demográfica, tanto do centro quanto do litoral do Brasil.

Dessa forma, a análise de Lourenço Filho reconhecia os avanços na organização do ensino primário de Mato Grosso, mas também apontava os problemas e indicava soluções, porque esse educador reconhecia, em sua vasta experiência, que essa era a única modalidade de educação que poderia ser oferecida à maioria das crianças mato-grossenses, por muito tempo.

\section{CONSIDERAÇÕES FINAIS}

O estado de Mato Grosso contava à época da produção e emissão do Boletim n. 22 com uma área de $1.477 .041 \mathrm{~km}$ e com uma população de 427.629 habitantes, distribuída em 28 municípios, ou seja, com baixa densidade demográfica e com vasta extensão territorial. Isso talvez explique e justifique a prevalência por muito tempo de escolas isoladas, sobretudo, rurais, até, pelo menos, os anos de 1940, e as parcas escolas de formação de professores normalistas no estado, por largo tempo. No entanto, a atenção dada ao estado por órgãos como o INEP, na figura de seu diretor, por exemplo, atesta a 
importância de que se foi revestindo tal estado na configuração da educação escolar do Brasil, haja vista o aumento considerável do número de escolas e de matrículas, tanto na escola primária quanto na escola normal, mesmo não vindo acompanhado de aumento qualitativo, conforme análise de Lourenço Filho (1942).

Investimentos foram garantidos e ampliação da oferta e da obrigatoriedade escolar foi conseguida, ao longo do tempo, a partir de então. Segundo Paes (2011), sem dúvida, o financiamento de construção de escolas em Mato Grosso foi, sobremaneira, o grande motor que alavancou a existência destas, em praticamente todos os povoamentos do meio rural, tendo sido a década de 1950, um divisor de águas.

O Boletim n. 22, sem dúvida nenhuma, contribuiu para esse estado de coisas. Ele aponta para uma política de medida e organização empreendida pelo INEP, marca também de seu diretor, Lourenço Filho, colocando em primeiro plano os avanços e as dificuldades da escola primária e normal mato-grossense e, talvez, por isso chamando para si a atenção necessária para a educação no Centro-Oeste do Brasil.

\section{REFERÊNCIAS}

BERTOLETTI, Estela Natalina Mantovani. Lourenço Filho e a alfabetização - um estudo de Cartilha do povo e da cartilha Upa, cavalinho!. São Paulo: Editora Unesp, 2006.

BRASIL. Ministério da Educação e Saúde. Decreto-Lei n. 580. Rio de Janeiro: INEP, 1938. Publicado no DOU de 30.07.1938

BRASIL. Ministério da Educação e Saúde. Organização do ensino primário e normal. XVII - Estado de Mato Grosso. Boletim n. 22. Rio de Janeiro: INEP, 1942.

BRASIL. Ministério da Educação. Instituto Nacional de Pesquisas Educacionais Anísio Teixeira. X Exposição de Obras Raras. Organização do ensino primário e normal nos Boletins do INEP. Acesso em: maio 2015. Disponível em: http://download.inep.gov.br/download/cibec/obras_raras/XV.pdf

CARVALHO, Manuel Marques. Lourenço Filho e o Instituto Nacional de Estudos Pedagógicos. IN: ASSOCIAÇÃO BRASILEIRA DE EDUCAÇÃO. Um educador brasileiro: Lourenço Filho. (Livro Jubilar organizado pela Associação Brasileira de Educação). São Paulo: Melhoramentos, 1959. p. 83-107.

LOURENÇO FILHO, Manoel Bergstrom. Introdução. In: BRASIL. Ministério da Educação e Saúde. Organização do ensino primário e normal. XVII - Estado de Mato Grosso. Boletim n. 22. Rio de Janeiro: INEP, 1942. p. 7-9. 
Antecedentes e primeiros tempos do INEP. Revista Brasileira de Estudos Pedagógicos, Brasília, v. 86, n. 212, p. 179-185, jan./abr. 2005. Disponível em: http://download.inep.gov.br/download/70Anos/Texto_Lourenco_Filho.pdf. Acesso em: jun. 2014.

MATO GROSSO. Regulamento da Instrução Pública do Estado de Mato Grosso. Cuiabá, 1927. Acesso em: jul. 2013.2 Disponível em: https://repositorio.ufsc.br/bitstream/handle/123456789/114996/Regulamento\%20MT\%201 927,\%2022\%20de\%20abril.pdf?sequence $=1$

MONARCHA, Carlos Roberto; LOURENÇO FILHO, Ruy (Org.). Por Lourenço Filho: uma biobibliografia. Brasília: INEP/MEC, 2001. p. 23-48.

MORTATTI, Maria do Rosário Longo. Os sentidos da alfabetização: São Paulo 1876/1994. São Paulo: Ed. Unesp, 2000.

PAES, Ademilson Batista. A escola primária rural em Mato Grosso no período republicano (1889-1942). 2011. Tese (Doutorado em Educação Escolar). Universidade Estadual Paulista “Júlio de Mesquita Filho", Araraquara, 2011.

Recebdo em : 10/01/2017

Aprovado em: 18/03/2017 